\title{
Experimental Investigation on the Ecofriendly External Wrapping of Glass Fiber Reinforced Polymer in Concrete Columns
}

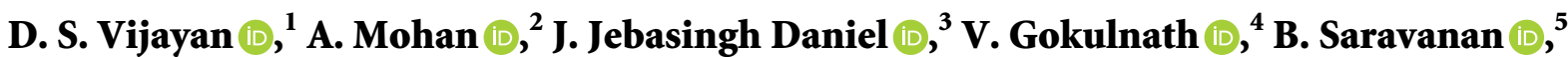 \\ and P. Dinesh Kumar $\mathbb{B D}^{6}$ \\ ${ }^{1}$ Department of Civil Engineering, Aarupadai Veedu Institute of Technology, Vinayaka Missions Research Foundation, \\ Paiyanoor, Chennai, India \\ ${ }^{2}$ Easwari Engineering College, Department of Civil Engineering, Ramapuram, Chennai, India \\ ${ }^{3}$ Department of Civil Engineering, Hawassa University, Hawassa, Ethiopia \\ ${ }^{4}$ Department of Civil Engineering, Saveetha School of Engineering, Saveetha Institute of Medical \& Technical Sciences, Chennai, \\ TN, India \\ ${ }^{5}$ Department of Civil Engineering, Aarupadai Veedu Institute of Technology, Vinayaka Missions Research Foundation, \\ Paiyanoor, Chennai, India \\ ${ }^{6}$ Head of the Department, Department of Civil Engineering, Krishnasamy College of Engineering and Technology, TN, India
}

Correspondence should be addressed to J. Jebasingh Daniel; jdaniel@hu.edu.et

Received 22 July 2021; Revised 16 August 2021; Accepted 19 August 2021; Published 29 August 2021

Academic Editor: Ravichandran M

Copyright (C) 2021 D. S. Vijayan et al. This is an open access article distributed under the Creative Commons Attribution License, which permits unrestricted use, distribution, and reproduction in any medium, provided the original work is properly cited.

\begin{abstract}
An ecofriendly fiber reinforced polymer (FRP) had been used in the last decade to enhance the short concrete column's strength and deformation capacity. This study involves the wrapping of FRP sheets with a thickness of $3 \mathrm{~mm}$ and $5 \mathrm{~mm}$ on a short column, and then the compressive strength is determined. The rectangular columns of size $150 \mathrm{~mm} \times 300 \mathrm{~mm}$ are used for this study, and cast under the grades of M20 and M40 are wrapped with GFRP sheets at the thickness of $3 \mathrm{~mm}$ and $5 \mathrm{~mm}$. These results are clarified at a specific thickness of the FRP-wrapped columns. It provides a maximum axial compressive strength, and Young's modulus gets enhanced rigorously when it is to be compared to the normal concrete. This thesis deals with experimental studies of different parameters associated with wrapped glass fiber reinforced polymer (GFRP). In M20 grade, when the $3 \mathrm{~mm}$ wrapped specimen and the $5 \mathrm{~mm}$ wrapped specimen are compared, the specimen wrapped with $5 \mathrm{~mm}$ increases $5.182 \%$ more than the specimen wrapped with $3 \mathrm{~mm}$. In M40 grade, when the $0 \mathrm{~mm}, 3 \mathrm{~mm}$, and $5 \mathrm{~mm}$ wrapped specimens are compared, the specimen wrapped with $5 \mathrm{~mm}$ increases $2.47 \%$ more than the specimen wrapped with $0 \mathrm{~mm}$. The $5 \mathrm{~mm}$ wrapping attains the maximum strength.
\end{abstract}

\section{Introduction}

Fiber reinforced polymer (FRP) is a composite material made up of a matrix reinforced with polymers. A vast amount of experimental work was conducted on FRP columns in the last decade. Natural disasters such as hurricanes, tornadoes, tsunamis, earthquakes, and unintended effects can destroy or damage the secondary structures in a matter of seconds. On the other hand, the salt water, chemical, and freeze-thaw cycles can induce structural degradation for a longer time [1]. Many old buildings and bridges were designed according to the old construction codes. FRP materials are a new technique that has gained popularity in recent years. As a result, these kinds of materials have been used for decades in other industries such as shipbuilding and defense, which provide novel solutions for rehabilitating decaying civil infrastructure. The continual deterioration of infrastructure has heightened awareness of the need for effective structure rehabilitation procedures. A peculiar challenging problem confronting engineers in the revival of the infrastructure is the rehabilitation of concrete structures. The use of externally bound FRP sheets and strips was 
developed recently as effective tools for rehabilitating and reinforcing concrete structures [2]. In the case of strength application, the external bonding FRP plates with column member were found to provide vast advantages: they are easy to handle, have resistance against electrochemical corrosion and fatigue resistance, have maintained good weight to strength ratio, are easy to use in curved casting with any shape and length, and provide maximum compressive strength at lesser density. [3] So, glass fiber enhanced polymer sheets are being used gradually to rehabilitate and upgrade the concrete structures when compared with other types of FRP fibers. The resistance to corrosion and fatigue is typically high in strength-to-weight [4].

Simple concrete has low voltage and little ductility and no cracking resistance. Because of the low tensile strength, microcracks are present in concrete. Cracks spread with load application leading to fragile concrete fractures. Over the last two decades, the use of GFRP as external wrapping has gained significant popularity for the reinforcement and repair of concrete structures. The GFRP wrapping was effectively used to improve and enhance existing structures and weak reinforced concrete components [5]. The external wrapping of reinforced concrete columns is a common technique for GFRP strengthening to increase the axial strength, sheer power, stiffness, and deflection. The GFRP sheet was mainly wrapped in the fiber direction around the columns in this application. The fiber limits the concrete cover and increases the strength and rigidity. Columns of reinforced concrete must be confined laterally to ensure a broad deformation under the applied loads before failure and to provide ample bearing capacity. As an axial compressive load is applied to the GFRP-wrapped concrete column, the concrete core extends laterally. The GFRP avoids this expansion, and the concrete core is transformed into a three-dimensional compressive stress state. There have been numerous investigations into the actions of the uniaxial compressive loaded GFRP-wrapped concrete column, which shows that fibers should be aligned along with the cement core.

In reality, however, almost all the columns suffer from an eccentric axial load that can be solved in a uniaxial time [6]. FRP is ideal for any design program that requires saving weight, precise engineering, finite tolerances, and simplifying components both in production and service. Molded polymer devices are cheaper, quicker, and easier to produce than cast aluminum or steel devices and retain tolerances and material strengths equally and often better [4]. Further, the strength, stress-strain ratios, elasticity, and failure under compression of externally reinforced concrete were studied. The test results indicated that FRP confinement increases the compressive and flexural strengths of concrete by approximately $22 \%$ and 1-2 MPa, respectively. Natural jute fibers (bark or straw) may be used as reinforcements for external concrete cylinders and prisms equally as polypropylene fibers. For external concrete confinement, natural jute FRP is recommended [7]. It was also suggested that a modified compression field formulation approximates the shear in stir-welded reinforced concrete due to piers that proved to be reliable. Steel stirrup yield was taken into account by including an empirical decay law. Because both FRP stress debonding and tensile stress were considered, the strain's influence on FRP reinforcement was sufficiently explored. It successfully matched experimental data, showing that it can accurately predict the shear strength. Numerical analysis was also calculated to show the significance of the key factors in predicting ultimate shear strength [8].

A new analytical model was designed to predict the compressive strength of FRP-filled concrete columns concerning the precontainment axial load level. To do so, several small concrete cylinders were loaded, subjected to a series of destructive tests of pure axial compression. It was confined with plastic reinforced carbon fiber. Four different levels of existing loads had been simulated, including the unloaded condition. The analytical predictions indicate that the FRP jacket's mechanical action is effective, but the presence of extensive damage precludes exploiting the confinement in the same way that unloaded columns would. The comparison of analytical predictions and experimental results appeared to be consistent, even though an additional investigation is required to validate the proposed theory [9]. Further, tests on both the control and strengthened beams were conducted. The control beams failed in shears, whereas the strengthened beam ductility failed, with most cracks protruding in a flexural length, indicating the successful shift of the failure mode from scissors to flexures by the integrated steel bars. In addition, the reinforced beam (Beam-B) has increased its strength by around $31 \%$ as compared to the beam control (Beam-A) [10].

Usually, the beams were tests with two axial loads. Results indicated that a maximum load of $9.78 \%$ and $9.92 \%$ increased respectively when compared to an acoustic beam with a single layer or two-layer abaca-fiber composite as NFRP material for the shear-foster beam. Abaca fiber composite NFRP material contributed $11 \%$ and $18.57 \%$ of the maximum total shear load for one-layer and two-layer laminates, respectively. Additionally, shear-strengthened beams that were externally bonded affected the crack pattern and deflection value. However, in two-layer NFRP shear strengthened beams, debonding failure of NFRP laminates occurred. As a result, the beam did not perform optimally [11]. The effect of high temperatures on the behavior of low solid cement following its consolidation in a polymer carbon fiber layer (CFRP) was further investigated. Among 84 specimens that have been examined, 42 have been wrapped in CFRP fibers and 42 have not been wrapped. Cylinder specimens $(150 \times 300 \mathrm{~mm})$ were used as a heat exposure period for one or two hours exposed to temperatures between $100^{\circ} \mathrm{C}$ and $600^{\circ} \mathrm{C}$. The practical part of the study focuses on compressive strength, ultrasonic pulse rate, dynamic elasticity modulus, and low strength concrete weight loss properties. The results indicated that when wrapped specimens were exposed to a temperature of $\left(200^{\circ} \mathrm{C}\right)$ for one and two hours, respectively, their compressive strength increased by $35 \%$ and $49 \%$, respectively, compared at the same level with unwrapped specimens. Furthermore, the external CFRP sheet strengthening acted as a protection for the concrete, improving the behavior of the low-strength concrete [12]. 
The current investigation considered reinforced concrete columns reflecting a real-world position in which reinforcement of the FRP is taken on reinforced concrete columns instead of plain concrete. The use of externally bonded FRP composites to reinforce and restore the existing concrete columns can be an economical option for restoring or enhancing their performance. While a great deal of research has focused on circular columns, there has been comparatively less work on square and rectangular columns to study the effects of FRP containment on structural efficiency. However, the majority of all columns are square or rectangular in houses. Therefore, the strength and restoration of building facilities must be maintained. This article is aimed at this endeavor. Efficient wrapping can increase the strength of both the confined cement and the carrying capacity of the column. This research aims to measure the effects of upgrading the carriage capability of GFP flexible wraps compressed concrete columns. For the different grades of concrete columns, the GFRP sheets of different thicknesses are wrapped, and the results are to be analyzed. The comparison was made regarding thickness of GFRP sheets, the maximum strength attained, and the wrapped columns and unwrapped columns.

\section{Material and Methods}

2.1. Fiber Reinforced Polymer. FRP is a composite material composed of a matrix reinforced with polymers. The different types of FRP are organized as organic FRP and inorganic structure. The various types of organic and inorganic fiber laminates structures are shown in Figures 1 and 2.

Roving is a group of strands, which are more of a uniform product. Woven roving provides an inexpensive way of laminating large, flat areas, for quick construction and reinforcement of high strength. It is incompatible with applications that require conformance. The material of woven roving laminated sheet is shown in Figure 3.

These are two-dimensional random arrays of chopped strands. The use of woven roving with chopped strand mat (CSM) is common in reinforcing other materials, and it is especially useful for making repairs. The CSM is incompatible with epoxy and should only be used with polyester or vinyl ester resin. The material of the CHM laminated sheet is shown in Figure 4.

Several forms are bonded with each other based on the type of output fiber needed. Combi mat, which is made by stitching woven fabric together with a layer of the chopped strand, is commonly known as "woven roving Combi mat." It is also compatible with polyesters with a degree of unsaturation, vinyl ester resins, and epoxy resins as well as polyphenols [13]. The woven roving Combi mat sheet is shown in Figure 5.

2.1.1. Cement and Aggregates. The most critical form of cement is Portland pozzolana. In compliance with IS 40311988 , the PPC was graded in three grades based on its intensity in 28 days. If the strength for 28 days is not less than $33 \mathrm{~N} / \mathrm{mm}^{2}$, it is referred to as a 33-grade cement, equivalent

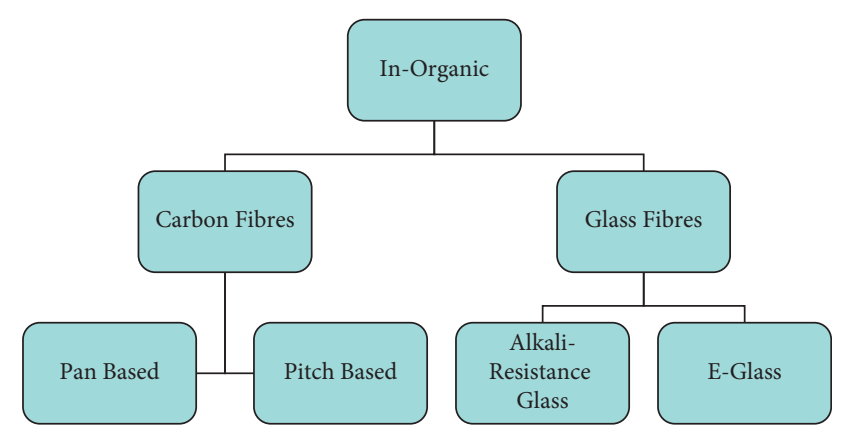

FIgURE 1: Inorganic structure of different types of fiber laminates.

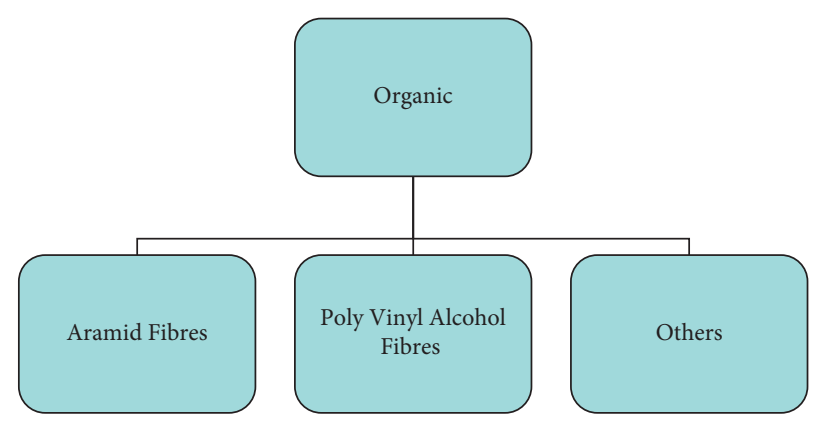

FIgURE 2: Organic structure of different types of fiber laminates.

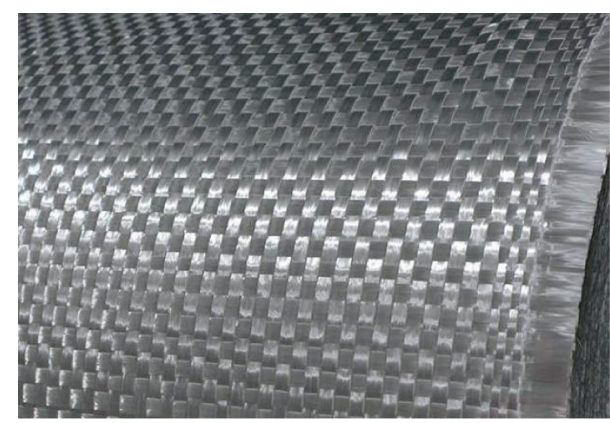

FIGURE 3: Woven roving laminated sheet.

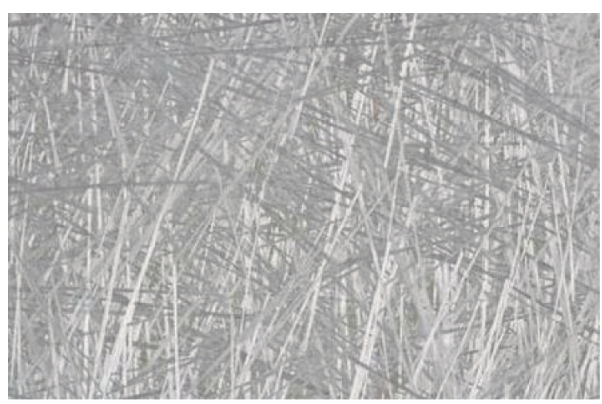

Figure 4: CHM laminated sheet.

to the wise one. If its strength is not less than $43 \mathrm{~N} / \mathrm{mm} 2$, it is called a 43 grade of cement. For future experiments, the Portland pozzolana cement of 53 grades was considered [14]. 


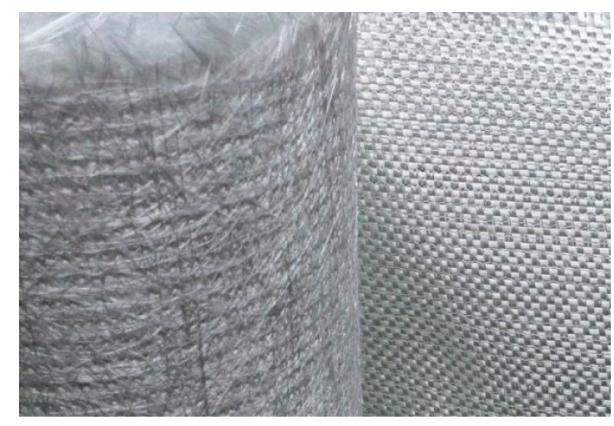

FIgURE 5: Woven roving Combi mat laminated sheet.

For this study, the 43 grade of cement was utilized based on the recommendation of previous researchers.

2.2. Testing of Cement. Testing of cement can be brought under two categories.

\subsection{Field Testing}

(i) The testing is done on the field itself, and it is sufficient for minor works.

(ii) Open the bag and take a good look at the cement.

(iii) There should not be any visible lumps, and the color should be greenish-grey.

(iv) When the hand is put into the cement bag, the feeling is incredible. After taking one pinch of cement and keeping it between the fingers, if it is a smooth and nongritty cement, then place it in a bucket full of water.

2.4. Laboratory Test. The following is usually done in the laboratory:

(i) The fine net should be smooth, and it should be applied with the concrete sample using resin. Let the sample to cure under room temperature for 28 days. After curing, the samples were tested and the results have to be analyzed based on the thickness of fine net.

(ii) A standard consistency test should be made.

(iii) The specific gravity of cement should be checked.

2.5. Fineness Test. The fine cement influences the hydration rate and the rate of increase in strength, as well as the rate of growth in heat. A cement sample should have a maximum particle count of fewer than 100 microns. Parts under 3 microns have a predominant impact on power, whereas 3-25 microns significantly affect 28 days of strength. The test is conducted under the standard guidelines of fineness of cement by dry sieving (IS: 4031-Part 1-1996).

2.6. Standard Consistency Test. The standard consistency test is designed to allow a $10 \mathrm{~mm}$ and $50 \mathrm{~mm}$ diameter VICAT PLUNGER to penetrate a depth of 33 . The mold top is
$35 \mathrm{~mm}$ in diameter. The VICAT system detects the percentage of water necessary to reach a standard consistency of cement. The test is conducted under the standard guidelines as Per IS Code 4031.

\subsection{Procedure for Consistency Test}

(i) Take some 500 grams of cement and plan for the first trial of the paste with a weighted quantity of water (24 percent cement weight).

(ii) The paste must be prepared regularly, and the Vic at mold must be filed within 3 to 5 minutes. After filling the mold fully, shake the mold to remove the air.

(iii) A $10 \mathrm{~mm}$ diameter, $50 \mathrm{~mm}$ standard long plunger is mounted, positioned to the surface if it is in the test block and released quickly so that it can fall into the paste due to its weight. Take the depth of penetration of the plunger by zero.

(iv) Conduct the second ( $25 \%$ water) test to determine the extent of penetration of the plunger. Similarly, conductivity is done daily, cement production for higher percentages of water and cement until the plunger penetrates the specified percentages of water from the top for a depth of 33-35 mm. Table 1 shows the cement test values.

2.8. Testing of Coarse Aggregate. The size of aggregate more significant than $4.75 \mathrm{~mm}$ is considered coarse aggregate and the primary source of aggregate. It increases the surface area, promotes workability, and calculates the amount of water absorbed by the coarse aggregates, while this experiment is conducted. The testing results are shown in Table 1 . The test is conducted under the standard guidelines as per code 383 for aggregates.

2.9. Testing for Fine Aggregate. The overall size of less than $4.75 \mathrm{~mm}$ is considered to be perfect [15]. The primary source of fine aggregates is pit sand from the river or the seaside. The type of river or shore bed sand is round, and pit sand is irregular or partly circular. The satisfactory aggregate test results are shown in Table 1. The test is conducted under the standard specification as per Is code 383 [1970] for aggregates.

2.10. Water. Water is the primary ingredient of concrete since it participates strongly in cement chemical reactions. Quantity and consistency participate with cement in the chemical reaction [16]. Water quantity and consistency must be studied very carefully. Optimization of portable water with $\mathrm{pH}$ values is between 6 and 8 and water is free of organic matter. The $\mathrm{pH}$ value of water was estimated as 12.3 with the comparison of standard buffer solutions.

2.11. GFRP Sheets. GFRP Sheets are a common name like carbon fiber or steel and are commercially available in different chemical compositions. The glass fibers are made 
TABLE 1: Test results for materials used in concrete.

\begin{tabular}{|c|c|c|c|c|}
\hline S.NO & Properties & Cement & $\begin{array}{c}\text { Coarse } \\
\text { aggregate }\end{array}$ & $\begin{array}{c}\text { Fine } \\
\text { aggregate }\end{array}$ \\
\hline 1 & Consistency & $33 \%$ & - & - \\
\hline 2 & Fineness & $\begin{array}{c}90 \\
\text { microns }\end{array}$ & 3.8 & 3.2 \\
\hline 3 & $\begin{array}{c}\text { Initial setting } \\
\text { time }\end{array}$ & $64 \mathrm{~min}$ & - & - \\
\hline 4 & Final setting time & $350 \mathrm{~min}$ & - & - \\
\hline 5 & Specific gravity & 3.15 & 20.7 & 2.67 \\
\hline 6 & $\begin{array}{c}\text { Water } \\
\text { absorption }\end{array}$ & - & 2.68 & - \\
\hline 7 & $\begin{array}{l}\text { Crushing } \\
\text { strength }\end{array}$ & - & 4.31 & - \\
\hline 8 & Zone & - & - & II \\
\hline
\end{tabular}

up of 3 groups E, S, and C. E-glass is used for electrical use, and S-glass is specified for a higher power. C-glass is highly resistant to corrosion and is not famous for civil engineering. Of the three fibers, E-glass is the reinforcement element most common in civil applications [2]. It was suggested that many of the features of the glass fiber need to be investigated throughly before application with different types of concrete.

Popular fibers are silica based and contain an array of other calcium, boron, sodium, aluminum, and iron oxides (50-60\% $\mathrm{SiO}_{2}$ ). Glass fibers have high tensile strength and elasticity modulus. The choice of materials for various enhancement systems is an essential process [17].

The fibers and resins are intended for collaboration. This resin for one reinforcement system will not work correctly for another reinforcement system. Thus, it is inferred that the qualitatively evaluated systems are used to improve intensity. The goal of adhesives is to create a continuous connection between the concrete surface and the material to ensure the complete composite action [18]. This was created by passing shear stress over the thickness of the adhesive sheet. The GFRP physical and chemical features of Tables 2 and 3 .

\section{Method and Preparation for GFRP Wrapping}

3.1. Grinding of Columns. The possibilities for sharp angles, except junctions, are negligible and the smooth surface needs to be ground and prepared; otherwise, air bubbles may occur when wrapping fiber. Grinding activity is necessary to remove the dust and cement loose layer [11]. Figure 6 depicts column grinding using gridding machine.

3.2. Selection of GFRP Sheets. Varieties of techniques are involved in the wrapping of GFRP. The unidirectional wrapping is selected because of the orientation of fibers. These fibers are usually arranged uniformly. So, the suitable sheets are to be selected for the strengthening effect. Figure 7 represents GFRP sheets used in concrete.

3.3. Mixing of Resin. Resins played an essential role in the GFRP wrapping. The resin mixture is applied to every layer
TABle 2: Properties of glass fiber.

\begin{tabular}{lc}
\hline Properties of glass fiber & Values \\
\hline The density of the fiber & $2.5 \mathrm{~g} / \mathrm{cm}^{3}$ \\
The thickness of the fiber sheet & $0.363 \mathrm{~mm}$ \\
Orientation of the fiber sheet & Bi-directional \\
Nominal thickness & $1 \mathrm{~mm}$ \\
Tensile strength of the fiber & $1.9-3.4 \mathrm{GPa}$ \\
The elasticity modulus of the fiber & $70 \mathrm{GPa}$ \\
\hline
\end{tabular}

TABle 3: Chemical composition of E-glass fiber.

\begin{tabular}{lc}
\hline Component & E-glass (\%weight) \\
\hline $\mathrm{SiO}_{2}$ & 55.2 \\
$\mathrm{~K}_{2} \mathrm{O}$ & 0.2 \\
$\mathrm{MgO}$ & 4.6 \\
$\mathrm{CaO}$ & 18.7 \\
$\mathrm{Na}_{2} \mathrm{O}$ & 0.3 \\
$\mathrm{Al}_{2} \mathrm{O}_{3}$ & 8.0 \\
\hline
\end{tabular}

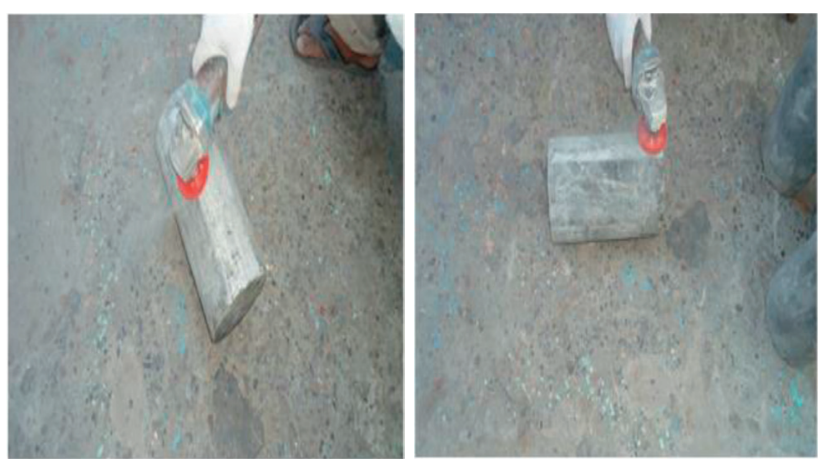

Figure 6: Grinding of columns.

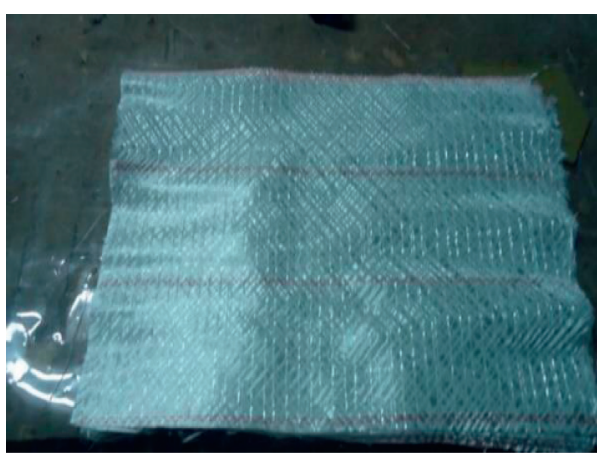

FIGURE 7: Selection of GFRP sheets.

of columns to seal the GFRP sheets [19]. Adding few drops of resin was considered as most challenging while mixing with the concrete [20]. The primary purpose of the epoxy resin is to harden the surface, as shown in Figure 8.

3.4. GFRP-Wrapped Columns. After applying the mixture of resins, the next step in the wrapping work is placing the GFRP sheets with a suitable thickness, and the setting of sheets 


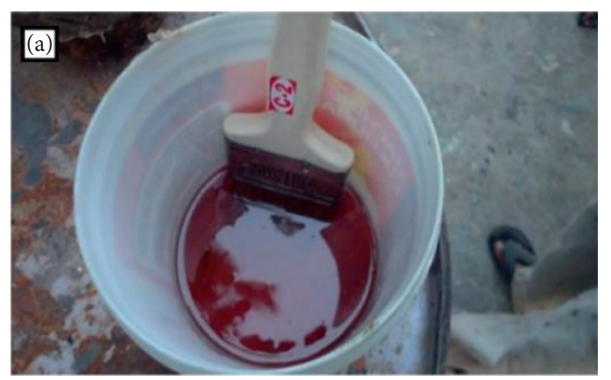

(a)

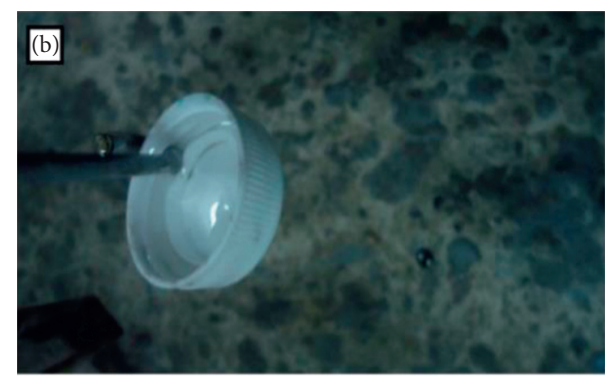

(b)

Figure 8: (a) Epoxy resin. (b) Mixing agent.

usually takes 3 hours. After setting the activity of wrapped columns, the unnecessary wastages at the top are to be cut, and the GFRP-wrapped columns are shown in Figure 6.

The casted specimen was wrapped with Glass FRP which is shown in Figure 9. The castings of the columns are made for two grades, i.e., M20 and M40. The size of the columns is $150 \mathrm{~mm} \times 300 \mathrm{~mm}$. The thickness of the wrapping is about $3 \mathrm{~mm}$ and $5 \mathrm{~mm}$. Now the compressive strength of the columns is to be tested, and then the results are to be analyzed: if thickness of wrapping can attain the maximum strength [8]. The comparison is made between the wrapped column and the unwrapped column [21]. The testing of the concrete beams is done for 28 days.

\section{Result and Discussion}

The experimental results are of M20 grade of columns and M40 grade of columns. First, the M20 grade of beams is taken. The specimens consist of the three columns in which two beams are wrapped with the GFRP of thickness $3 \mathrm{~mm}$ and $5 \mathrm{~mm}$; one beam remains unwrapped with any sheets. Now the compressive strength of the beam is tested [9]. Here the wrapped beams will attain the maximum compressive strength when it is compared to the unwrapped beam. The test results are compared with the two thicknesses of the columns, and the maximum compressive strength is evaluated. A similar experiment is repeated for the M40 grade of concrete.

4.1. Testing of GFRP-Wrapped Columns. The wrapping of GFRP sheets is kept as it is for 48 hours. The specimens are ready for testing, the extensometer is fixed along with the columns, and the specimen is placed in the compressive testing machine [22]. The load is gradually applied and the deflection is to be noted. Figure 10(a) shows the arrangement of experimental setup and (b) depicts the experimental set up to test the specimens.

4.2. Testing of GFRP-Wrapped M20 Grade Concrete Columns with $0 \mathrm{~mm}$ Wrapping. When the column was cast under the grade of M20 and then the testing is made after 28 days, the compressive strength of the cube is about $236 \mathrm{kN}$. The column was cast under the grade of M40, and then the testing is made after 28 days. The compressive strength of the cube is about
$387 \mathrm{kN}$. The quantity is a ratio of stress along an axis to the stress of the hook law [23]. Table 4 displays Young's M20 module with $0 \mathrm{~mm}$ stroke, and Figure 11 represents stressstrain analysis for M20 concrete with $0 \mathrm{~mm}$ wrapping.

Testing of GFRP-wrapped M40 grade concrete columns with $0 \mathrm{~mm}$ wrapping.

The Young's modulus for the grade of M40 with $0 \mathrm{~mm}$ wrapping is shown in Table 5, and the stress-strain analysis curve is shown in Figure 12.

\subsection{Testing of GFRP-Wrapped M20 Grade Concrete Columns} with $3 \mathrm{~mm}$ Wrapping. The Young's modulus for grade M20 with $3 \mathrm{~mm}$ wrapping is shown in Table 6 , and the stressstrain analysis curve is shown in Figure 13. The column was cast and, after the curing, wrapping of the GFRP sheet is done with a thickness of $3 \mathrm{~mm}$ under the grade of M20. After that the specimen is tested in the compressive testing machine, and it attains the load of $1184 \mathrm{kN}$.

Testing of GFRP-wrapped M20 grade concrete columns with $5 \mathrm{~mm}$ wrapping.

The Young's modulus for grade M20 with $5 \mathrm{~mm}$ wrapping is shown in Table 7, and the stress-strain analysis curve is shown in Figure 14. The column was cast and after the curing, wrapping of the GFRP sheet is done with a thickness of $5 \mathrm{~mm}$ under grade M20. Now that the specimen is tested in the compressive testing machine, it attains a load of $1073 \mathrm{kN}$.

Testing of GFRP-wrapped M40 grade concrete columns with $3 \mathrm{~mm}$ wrapping.

The Young's modulus for grade M40 with $3 \mathrm{~mm}$ wrapping is shown in Table 8 , and the stress-strain analysis curve is shown in Figure 15. The column was cast, and after the curing, wrapping of the GFRP sheet is done with a thickness of $3 \mathrm{~mm}$ under grade M40. Now that the specimen is tested in the compressive testing machine, it attains a load of $1171 \mathrm{kN}$.

\subsection{Testing of GFRP-Wrapped M40 Grade Concrete Columns} with $5 \mathrm{~mm}$ Wrapping. The Young's modulus for grade M40 with $5 \mathrm{~mm}$ wrapping is shown in Table 9, and the stressstrain analysis curve is shown in Figure 16. The column was cast, and after the curing, wrapping of the GFRP sheet is done to the thickness of $5 \mathrm{~mm}$ under the grade of M40. Now that the specimen is tested in the compressive testing machine, it attains a load of $1235 \mathrm{kN}$. 


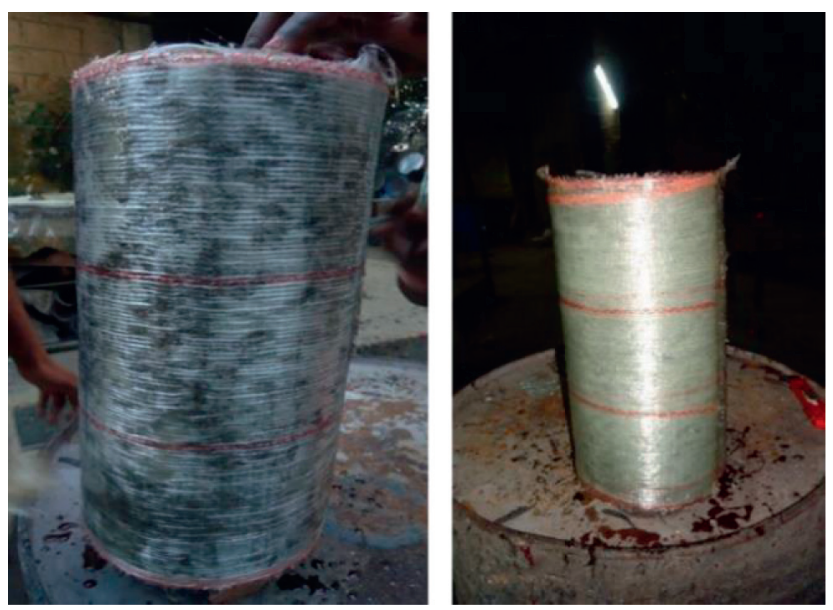

FIGURE 9: GFRP-wrapped columns.

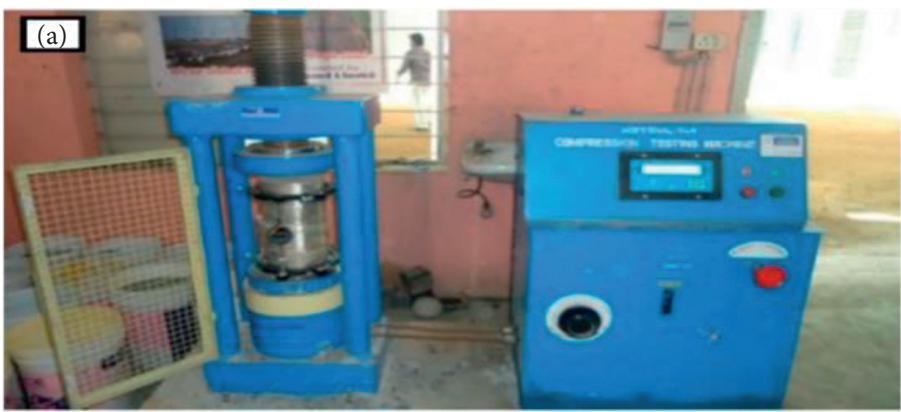

(a)

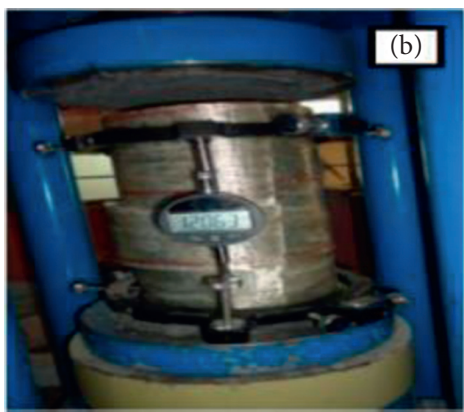

(b)

Figure 10: (a) Arrangement of experimental set. (b) Testing of GFRP-wrapped columns in compression testing machine.

TABLE 4: Young's modulus for M20 grade of the column with $0 \mathrm{~mm}$ wrapping.

\begin{tabular}{lccccc}
\hline S.No & Load $(\mathrm{kN})$ & Deflection $(\mathrm{mm})$ & Stress $\left(\mathrm{N} / \mathrm{mm}^{2}\right)$ & Strain $\times 10^{-5}$ & Young's modulus E \\
\hline 1 & 20 & 0.036 & 1.13 & 1.2 & 0.94 \\
2 & 40 & 0.076 & 2.26 & 36.3 & 0.9 \\
3 & 60 & 0.109 & 3.39 & 44 & 0.09 \\
4 & 80 & 0.132 & 4.52 & 52 & 0.102 \\
5 & 100 & 0.156 & 5.65 & 59.6 & 0.108 \\
6 & 120 & 0.179 & 6.79 & 69.6 & 0.113 \\
7 & 140 & 0.209 & 7.92 & 75.3 & 0.113 \\
8 & 160 & 0.226 & 9.05 & 78.0 & 0.120 \\
9 & 180 & 0.234 & 10.18 & 82.3 & 0.130 \\
10 & 200 & 0.247 & 11.32 & 86.2 & 0.144 \\
11 & 220 & 0.258 & 12.44 & & \\
\hline
\end{tabular}

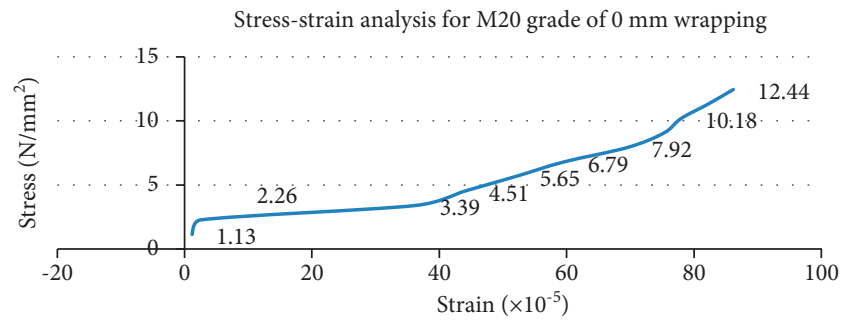

FIGURE 11: Stress-strain analysis for grade M20 with $0 \mathrm{~mm}$ wrapping. 
TABle 5: Young's modulus for M40 grade of the column with $0 \mathrm{~mm}$ wrapping.

\begin{tabular}{|c|c|c|c|c|c|}
\hline S. No & Load $(\mathrm{kN})$ & Deflection $(\mathrm{mm})$ & Stress $\left(\mathrm{N} / \mathrm{mm}^{2}\right)$ & Strain $\times 10^{-5}$ & Young's modulus E \\
\hline 1 & 20 & 0.002 & 1.13 & 0.67 & 1.68 \\
\hline 2 & 40 & 0.009 & 2.26 & 3 & 0.75 \\
\hline 3 & 60 & 0.02 & 3.39 & 6.66 & 0.5 \\
\hline 4 & 80 & 0.030 & 4.52 & 10 & 0.45 \\
\hline 5 & 100 & 0.036 & 5.65 & 12 & 0.47 \\
\hline 6 & 120 & 0.054 & 6.79 & 18 & 0.37 \\
\hline 7 & 140 & 0.072 & 7.92 & 24 & 0.33 \\
\hline 8 & 160 & 0.088 & 9.05 & 29 & 0.3 \\
\hline 9 & 180 & 0.111 & 10.18 & 37.4 & 0.27 \\
\hline 10 & 200 & 0.142 & 11.31 & 47.3 & 0.23 \\
\hline 11 & 220 & 0.174 & 12.44 & 58 & 0.21 \\
\hline 12 & 240 & 0.207 & 13.58 & 69 & 0.19 \\
\hline 13 & 260 & 0.242 & 14.71 & 80.6 & 0.18 \\
\hline 14 & 280 & 0.730 & 15.84 & 243 & 0.06 \\
\hline 15 & 300 & 0.697 & 16.97 & 232 & 0.07 \\
\hline 16 & 320 & 0.648 & 18.10 & 216 & 0.08 \\
\hline 17 & 340 & 0.613 & 19.24 & 204 & 0.09 \\
\hline 18 & 360 & 0.578 & 20.3 & 192 & 0.10 \\
\hline 19 & 380 & 0.538 & 21.50 & 179 & 0.12 \\
\hline
\end{tabular}

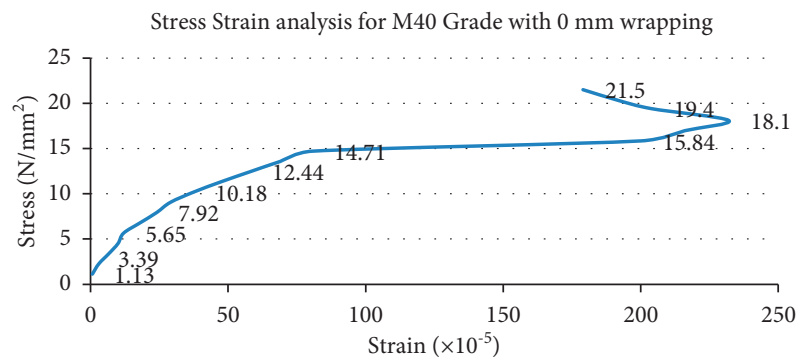

Figure 12: Stress-strain analysis for grade M40 with $0 \mathrm{~mm}$ wrapping.

TABLE 6: Young's modulus for M20 grade of column with $3 \mathrm{~mm}$ wrapping.

\begin{tabular}{|c|c|c|c|c|c|}
\hline S.No & Load $(\mathrm{kN})$ & Deflection $(\mathrm{mm})$ & Stress $\left(\mathrm{N} / \mathrm{mm}^{2}\right)$ & Strain $\left(\times 10^{-5}\right)$ & Young's modulus E \\
\hline 1 & 50 & 0.550 & 2.829 & 1.83 & 0.15 \\
\hline 2 & 100 & 0.236 & 5.658 & 7.86 & 0.70 \\
\hline 3 & 150 & 0.758 & 8.488 & 2.52 & 0.33 \\
\hline 4 & 200 & 1.363 & 11.317 & 4.54 & 0.24 \\
\hline 5 & 250 & 2.872 & 14.145 & 9.57 & 0.14 \\
\hline 6 & 300 & 2.418 & 16.972 & 8.06 & 0.21 \\
\hline 7 & 350 & 2.760 & 19.805 & 9.20 & 0.23 \\
\hline 8 & 400 & 4.026 & 22.635 & 13.42 & 0.16 \\
\hline 9 & 450 & 4.355 & 25.464 & 14.51 & 0.17 \\
\hline 10 & 500 & 4.692 & 28.294 & 15.42 & 0.18 \\
\hline 11 & 550 & 4.927 & 31.123 & 16.42 & 0.18 \\
\hline 12 & 600 & 5.274 & 33.953 & 17.58 & 0.19 \\
\hline 13 & 650 & 5.515 & 36.782 & 18.38 & 0.20 \\
\hline 14 & 700 & 7.879 & 39.611 & 26.26 & 0.15 \\
\hline 15 & 750 & 8.143 & 42.441 & 27.14 & 0.15 \\
\hline 16 & 800 & 10.476 & 45.270 & 34.93 & 0.12 \\
\hline 17 & 850 & 11.721 & 48.100 & 39.07 & 0.12 \\
\hline 18 & 900 & 15.972 & 50.929 & 53.24 & 0.09 \\
\hline 19 & 950 & 15.402 & 53.759 & 51.34 & 0.01 \\
\hline 20 & 1000 & 17.134 & 56.588 & 57.11 & 0.09 \\
\hline 21 & 1050 & 18.920 & 59.417 & 63.06 & 0.09 \\
\hline 22 & 1100 & 20.825 & 62.247 & 69.41 & 0.08 \\
\hline 23 & 1150 & 22.568 & 65.076 & 75.22 & 0.08 \\
\hline
\end{tabular}




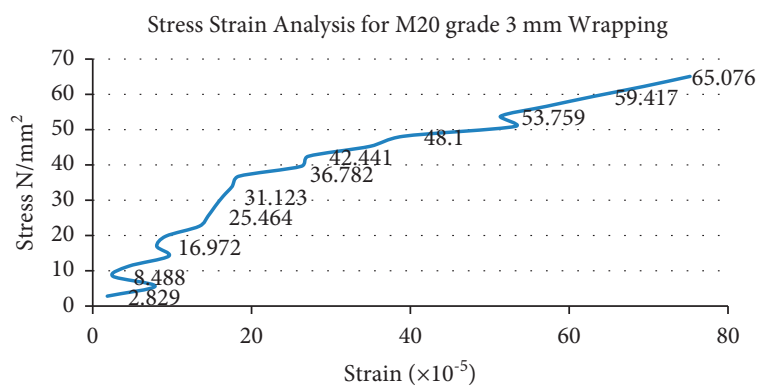

Figure 13: Stress-strain analysis for grade M20 with $3 \mathrm{~mm}$ wrapping.

TABLE 7: Young's modulus for M20 grade of column with $5 \mathrm{~mm}$ wrapping.

\begin{tabular}{lccccc}
\hline S.No & Load $(\mathrm{kN})$ & Deflection $(\mathrm{mm})$ & Stress $\left(\mathrm{N} / \mathrm{mm}^{2}\right)$ & Strain $\left(\times 10^{-5}\right)$ & Young's modulus E \\
\hline 1 & 50 & 0.160 & 2.830 & 5.333 & 0.5300 \\
2 & 100 & 0.335 & 5.658 & 1.116 & 0.5069 \\
3 & 150 & 0.524 & 8.488 & 2.746 & 0.4861 \\
4 & 200 & 0.681 & 11.317 & 2.684 & 0.4978 \\
5 & 250 & 0.804 & 14.147 & 3.426 & 0.5270 \\
6 & 300 & 1.028 & 16.976 & 4.413 & 0.4955 \\
7 & 350 & 1.324 & 19.805 & 5.566 & 0.4487 \\
8 & 400 & 1.670 & 22.635 & 7.116 & 0.4066 \\
9 & 450 & 2.135 & 25.464 & 8.416 & 0.3578 \\
10 & 500 & 2.525 & 28.294 & 9.646 & 0.3361 \\
11 & 550 & 2.894 & 31.123 & 14.616 & 0.3288 \\
12 & 600 & 4.385 & 33.953 & 17.613 & 0.2323 \\
13 & 650 & 3.784 & 36.782 & 15.260 & 0.2916 \\
14 & 700 & 5.195 & 39.611 & 20.450 & 0.2287 \\
15 & 750 & 4.578 & 42.441 & 25.260 & 0.2781 \\
16 & 800 & 6.135 & 45.270 & 30.273 & 0.2213 \\
17 & 850 & 7.578 & 48.100 & 59.213 & 0.1904 \\
18 & 900 & 9.082 & 50.930 & 68.260 & 0.1682 \\
19 & 950 & 17.764 & 53.760 & 56.588 & 0.0097 \\
20 & 1000 & 20.478 & & & 0.0082 \\
\hline
\end{tabular}

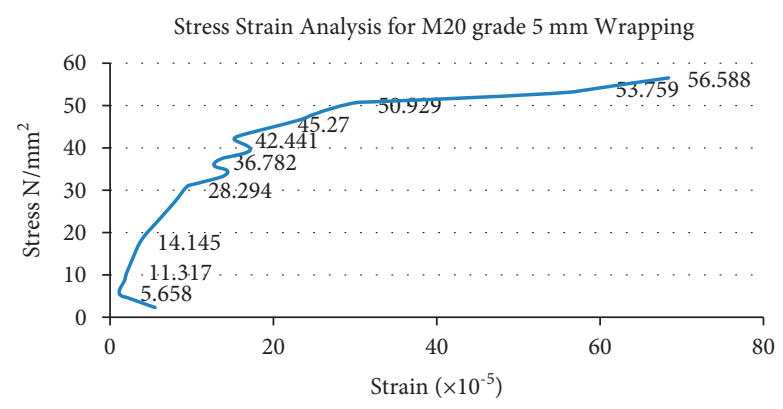

FIgURE 14: Stress-strain analysis for grade M20 with $5 \mathrm{~mm}$ wrapping.

In the grade of $\mathrm{M} 20$, the thickness of $3 \mathrm{~mm}$ attains the maximum load, and in the grade of M40, the thickness of $5 \mathrm{~mm}$ attains the maximum load. In case of M20 grade, when we compare the unwrapped specimen with the $3 \mathrm{~mm}$ wrapped specimen column, there is an increase of $80.06 \%$ more than the unwrapped column. In the case of M20 grade, when we compare the unwrapped specimen with the $5 \mathrm{~mm}$ wrapped specimen, the wrapped column increases $78.00 \%$ more than the unwrapped column. In M20 grade, when we compare the $3 \mathrm{~mm}$ wrapped specimen with the $5 \mathrm{~mm}$ wrapped specimen, the specimen wrapped with $3 \mathrm{~mm}$ increases $9.375 \%$ more than the specimen wrapped with $5 \mathrm{~mm}$. In case of M40 grade, when we compare the unwrapped specimen with the $3 \mathrm{~mm}$ wrapped specimen, the wrapped column increases $66.96 \%$ more than the unwrapped column. In M40 grade, when we compared the unwrapped specimen 
TABLE 8: Young's modulus for M40 grade of column with $3 \mathrm{~mm}$ wrapping.

\begin{tabular}{lccccc}
\hline S.No & Load $(\mathrm{kN})$ & Deflection $(\mathrm{mm})$ & Stress $\left(\mathrm{N} / \mathrm{mm}^{2}\right)$ & Strain $\left(\times 10^{-5}\right)$ & Young's modulus E \\
\hline 1 & 50 & 0.030 & 2.830 & 1.000 & 0.283 \\
2 & 100 & 0.070 & 5.658 & 2.333 & 0.242 \\
3 & 150 & 0.119 & 8.488 & 5.970 & 0.213 \\
4 & 200 & 0.161 & 11.317 & 6.733 & 0.210 \\
5 & 250 & 0.202 & 14.147 & 8.170 & 0.210 \\
6 & 300 & 0.245 & 16.976 & 9.533 & 0.207 \\
7 & 350 & 0.286 & 19.805 & 1.126 & 0.207 \\
8 & 400 & 0.338 & 22.635 & 1.336 & 0.201 \\
9 & 450 & 0.401 & 25.464 & 1.560 & 0.190 \\
10 & 500 & 0.468 & 28.294 & 2.023 & 0.181 \\
11 & 550 & 0.545 & 31.123 & 2.233 & 0.167 \\
12 & 600 & 0.607 & 33.953 & 2.453 & 0.164 \\
13 & 650 & 0.670 & 36.782 & 2.676 & 0.161 \\
14 & 700 & 0.736 & 39.611 & 2.930 & 0.158 \\
15 & 750 & 0.803 & 42.441 & 3.206 & 0.154 \\
16 & 800 & 0.879 & 45.270 & 3.556 & 0.150 \\
17 & 850 & 0.962 & 48.100 & 4.053 & 0.132 \\
18 & 900 & 1.067 & 50.930 & 5.760 & 0.118 \\
19 & 950 & 1.216 & 53.760 & 5.833 & \\
20 & 1000 & 1.428 & 56.588 & 5.417 & \\
21 & 1050 & 1.750 & & &
\end{tabular}

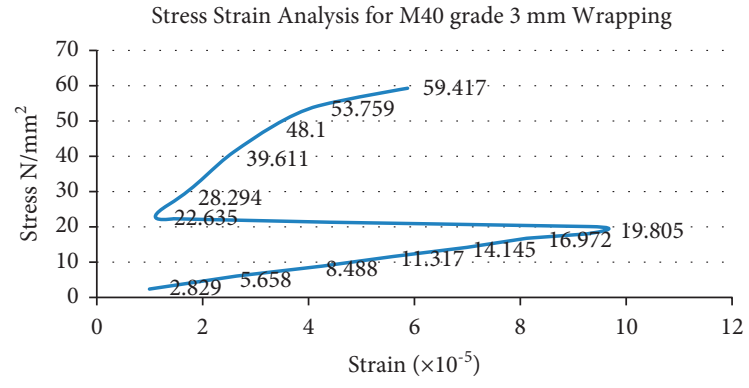

FIgURE 15: Stress-strain analysis for grade M40 with $3 \mathrm{~mm}$ wrapping.

TABLE 9: Young's modulus for M40 grade of column with $5 \mathrm{~mm}$ wrapping.

\begin{tabular}{|c|c|c|c|c|c|}
\hline S.No & Load $(\mathrm{kN})$ & Deflection $(\mathrm{mm})$ & Stress $\left(\mathrm{N} / \mathrm{mm}^{2}\right)$ & Strain $\left(\times 10^{-5}\right)$ & Young's modulus E \\
\hline 1 & 50 & 0.0720 & 2.830 & 2.400 & 0.117 \\
\hline 2 & 100 & 0.120 & 5.658 & 4.000 & 0.141 \\
\hline 3 & 150 & 0.183 & 8.488 & 6.100 & 0.139 \\
\hline 4 & 200 & 0.262 & 11.317 & 8.733 & 0.129 \\
\hline 5 & 250 & 0.321 & 14.147 & 1.070 & 0.132 \\
\hline 6 & 300 & 0.380 & 16.976 & 1.270 & 0.133 \\
\hline 7 & 350 & 0.437 & 19.805 & 1.455 & 0.136 \\
\hline 8 & 400 & 0.501 & 22.635 & 1.670 & 0.135 \\
\hline 9 & 450 & 0.564 & 25.464 & 1.880 & 0.135 \\
\hline 10 & 500 & 0.633 & 28.294 & 2.110 & 0.134 \\
\hline 11 & 550 & 0.693 & 31.123 & 2.310 & 0.134 \\
\hline 12 & 600 & 0.770 & 33.953 & 2.570 & 0.132 \\
\hline 13 & 650 & 0.881 & 36.782 & 2.930 & 0.125 \\
\hline 14 & 700 & 0.040 & 39.611 & 1.333 & 0.297 \\
\hline 15 & 750 & 0.131 & 42.441 & 4.370 & 0.097 \\
\hline 16 & 800 & 0.263 & 45.270 & 8.770 & 0.051 \\
\hline 17 & 850 & 0.409 & 48.100 & 1.363 & 0.352 \\
\hline 18 & 900 & 0.532 & 50.930 & 1.773 & 0.287 \\
\hline 19 & 950 & 0.780 & 53.760 & 2.600 & 0.206 \\
\hline
\end{tabular}


TABle 9: Continued.

\begin{tabular}{lccccc}
\hline S.No & Load $(\mathrm{kN})$ & Deflection $(\mathrm{mm})$ & Stress $\left(\mathrm{N} / \mathrm{mm}^{2}\right)$ & Strain $\left(\mathrm{x} 10^{-5}\right)$ & Young's modulus E \\
\hline 20 & 1000 & 0.923 & 56.588 & 3.076 & 0.183 \\
21 & 1050 & 1.014 & 59.417 & 3.380 & 0.175 \\
22 & 1100 & 1.195 & 62.244 & 3.988 & 0.156 \\
23 & 1150 & 1.351 & 65.076 & 4.503 & 0.144 \\
24 & 1200 & 1.581 & 67.906 & 5.270 & 0.128 \\
25 & 1250 & 1.794 & 70.735 & 5.980 & 0.118 \\
\hline
\end{tabular}

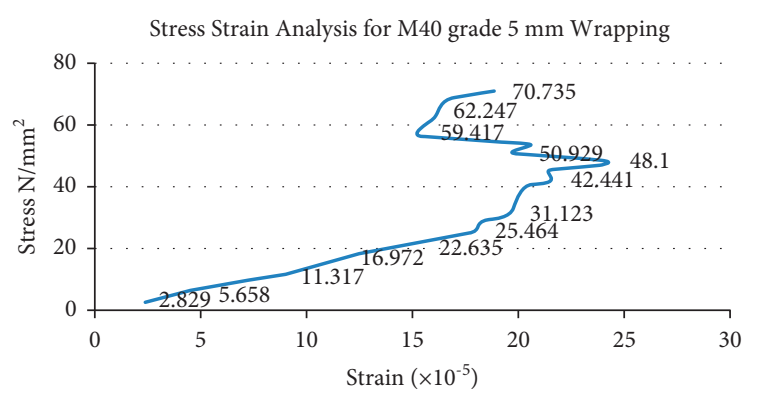

FIGURE 16: Stress-strain analysis for grade M40 with $5 \mathrm{~mm}$ wrapping.

with the $5 \mathrm{~mm}$ wrapped specimen, the wrapped column increases $68.66 \%$ more than the unwrapped column.

\section{Conclusion}

The experimental work carried out in this study concentrated primarily on determining the efficacy of concrete columns filled with reinforced polymer glass fiber. The experimental findings from experiments on concrete columns were reinforced by external E-glass fiber composite in load capacity and strains. In case of M40 grade, when the $3 \mathrm{~mm}$ wrapped specimen and the $5 \mathrm{~mm}$ wrapped specimen are compared, the specimen wrapped with $5 \mathrm{~mm}$ increases $5.182 \%$ more than the specimen wrapped with $3 \mathrm{~mm}$. In M40 grade, when the $0 \mathrm{~mm}, 3 \mathrm{~mm}$, and $5 \mathrm{~mm}$ wrapped specimen are compared, the specimen wrapped with $5 \mathrm{~mm}$ increases $2.47 \%$ more than the specimen wrapped with $0 \mathrm{~mm}$. The $5 \mathrm{~mm}$ wrapping attains the maximum strength.

\subsection{Future Work}

(i) The GFRP materials are not providing satisfactory outcomes for creep and heavy sustained loads, hence increasing thickness or adding adequate materials as a support to resist the creep.

(ii) Impact loading causes more damage to GFRP concrete structural elements. So, providing ductile detailing could be the best solution for future research.

(iii) GFRP design should be improved to adapt to different environmental changes since it shows poor results in high temperature.

(iv) The elastic modulus of GFRP is significantly less compared to steel and concrete. It would be better if research has been carried out in this area to enhance elastic modulus. (v) Adequate code provisions should be developed to fix the proportion of fiber used in concrete since it makes changes in concrete strength.

\section{Data Availability}

The data used to support the findings of this study are available upon request.

\section{Conflicts of Interest}

The authors declare that there are no conflicts of interest regarding the publication of this article.

\section{Acknowledgments}

Research outcomes of the manuscript were supported by the Department of Civil Engineering, Krishnasamy College of Engineering and Technology, Chennai. The authors would also like to extend their thanks to the authors and nontechnical staff of Aarupadai Veedu Institute of Technology, Chennai, SRM Easwari Engineering College, and Saveetha School of Engineering for providing the needed technical support.

\section{References}

[1] S. Robert Ravi and G. Prince Arulraj, "Experimental investigation on the behavior of R.C.C. Beams-column joints retrofitted with GFRP-CFRP hybrid wrapping subjected to load reversal," International Journal of Mechanics and Solids.ISSN, vol. 5, no. 1, pp. 973-1881, 2010.

[2] C. E. Chalioris, "Tests and analysis of reinforced concrete beams under torsion retrofitted with FRP strips," in Proceedings of the 13th Computational Methods and Experimental Measurements (CMEM 2007), vol. 11, Prague, Czech Republic, 2007. 
[3] B. Ramesh, S. Eswari, and T. Sundararajan, "Flexural behaviour of glass fiber reinforced polymer (GFRP) laminated hybrid-fiber reinforced concrete beams," SN Applied Sciences, vol. 2, no. 2, p. 204, 2020.

[4] D. Parthiban, D. S. Vijayan, R. Sanjay Kumar, A. P. Santhu, G. Abraham Cherian, and M. Ashiq, "Performance evaluation of Fly ash based GPC with partial replacement of RHA as a cementitious material," Materials Today: Proceedings, vol. 33, pp. 550-558, 2020.

[5] M. N. Mahmood and A. Sh. Mahmood, "Torsional behavior of prestressed concrete beam strengthened with CFRP sheets," in Proceedings of the 16th International Conference on Composite Structures, ICCS, vol. 16, p. 14, Porto, Portugal, June 2011.

[6] D. S. Vijayan and J. Revathy, "Flexural response of fibre reinforced polymer laminated pre-stressed concrete beams," Indian Journal of Science and Technology, vol. 9, no. 42, 2016.

[7] K. Madhavi, V. V. Harshith, M. Gangadhar, V. Chethan Kumar, and T. Raghavendra, "External strengthening of concrete with natural and synthetic fiber compositesfiber Composites," Materials Today: Proceedings, vol. 38, pp. 2803-2809, 2021.

[8] N. Spinella, P. Colajanni, A. Recupero, and F. Tondolo, "Ultimate shear of RC beams with corroded stirrups and strengthened with FRP," Buildings, vol. 9, no. 2, p. 34, 2019.

[9] F. Micelli, A. Cascardi, and M. A. Aiello, "Pre-load effect on CFRP-confinement of concrete columns: experimental and theoretical studyfinement of concrete columns: experimental and theoretical study," Crystals, vol. 11, no. 2, p. 177, 2021.

[10] Ridwan, S. Dirar, Y. Jemaa, A. Kamaldi, and A. Kurniawandy, "Strengthening of reinforced concrete beam subjected to shear loading using deep embedment method," Journal of Physics: Conference Series, vol. 1655, Article ID 012089, 2020.

[11] T. Saidi, Z. Amalia, M. Hasan, I. Hasanuddin, and K. Setiawan, "Number of layer effect of abaca fiber as natural FRP material for shear-strengthened reinforced concrete beam," IOP Conference Series: Materials Science and Engineering, vol. 1087, no. 1, Article ID 012006, 2021.

[12] R. D. Shlla and K. I. Mohammad, "Experimental investigation on CFRP-confined low strength concrete after high-temperatures exposure," IOP Conference Series: Materials Science and Engineering, vol. 1094, no. 1, Article ID 012086, 2021.

[13] M. Dong, W. Lokuge, M. Elchalakani, and A. Karrech, "Modelling glass fiber-reinforced polymer reinforced geopolymer concrete columns," Structure, vol. 20, pp. 813-821, 2019.

[14] A. Acharya, S. Reddy, and K. Savaliya, "Effect of glass fibre reinforced polymer wrapping on strength of confined concrete," International Journal of Technical Innovation in Modern Engineering \& Science (IJTIMES), vol. 3, no. 5, 2017.

[15] V. Sreevidya and M. Ponkishan, "Strength evaluation of retrofitted geopolymer concrete using natural fibre," International Research Journal of Engineering and Technology (IRJET), vol. 7, no. 9, Sep 2020.

[16] R. Nandhini, Dr. M. M. Saravanan, and A. Karunya Grace, "Retrofitting of concrete structures using fibre reinforced polymer (FRP): a review," International Journal of Scientific \& Technology Research, vol. 9, no. 2, 2020.

[17] D. S. Vijayan and D. Parthiban, "Effect of Solid waste based stabilizing material for strengthening of Expansive soil- A review," Environmental Technology \& Innovation, vol. 20, Article ID 101108, 2020.

[18] Ajidevi, "Experimental investigation on Properties of concrete using glass fibre," International Journal of Engineering Research \& Technology (IJERT), vol. 4, no. 8.
[19] A. Fitria, A. Saloma, S. A. Nurjannah, and A. P. Usman, "Numerical analysis of the behavior of light concrete panels with variations of thickness and door opening position in resisting static monotonic loads," International Journal of Advanced Technology and Engineering Exploration, vol. 7, no. 73, 2021.

[20] R. Raval and U. Dave, "Behavior of GFRP wrapped RC columns of different shapes," Procedia Engineering, vol. 51, pp. 240-249, 2013.

[21] B. Saravanan and D. S. Vijayan, "Status review on the experimental investigation on replacement of red-mud in cementitious concrete," Materials Today: Proceedings, vol. 33, pp. 593-598, 2020.

[22] A. Zhou, C. L. Chow, and D. Lau, "Structural behavior of GFRP reinforced concrete columns under the influence of chloride at casting and service stages," Composites Part B: Engineering, vol. 136, pp. 1-9, 2018.

[23] D. Parthiban and D. S. Vijayan, "Study on Stress-Strain effect of reinforced Metakaolin based GPC under compression," Materials Today: Proceedings, vol. 22, pp. 822-828, 2020. 